\title{
"VERTICAL MULCHING" COMO PRÁTICA CONSERVACIONISTA PARA MANEJO DE ENXURRADA EM SISTEMA PLANTIO DIRETO ${ }^{(1)}$
}

\author{
José Eloir Denardin ${ }^{(2)}$, Rainoldo Alberto Kochhann ${ }^{(2)}$, Antônio Faganello ${ }^{(2)}$, Arcenio \\ Sattler $^{(2)}$ \& Diego Denardin Manhago ${ }^{(3)}$
}

\begin{abstract}
RESUMO
Nas regiões brasileiras de clima temperado e subtropical úmido, situadas ao sul do paralelo $24^{\circ}$ de latitude sul, as características fundamentais da chuva apresentam potencial para superar a taxa de infiltração de água no solo e gerar enxurrada, em qualquer época do ano, independentemente do uso e do manejo de solo. O sistema plantio direto não tem sido implementado com a plenitude das práticas conservacionistas requeridas pelas condições de solo dessas regiões do País para conter o potencial erosivo de chuvas intensas. A enxurrada resulta na produção de sedimento enriquecido por agroquímicos, que, além de promover prejuízos econômicos ao sistema agrícola produtivo, pode afetar a ambiência. Este trabalho teve por objetivo avaliar a eficiência da prática conservacionista vertical mulching no manejo de enxurrada em lavouras sob sistema plantio direto, por meio da quantificação do índice de enriquecimento do sedimento. O estudo contemplou amostragens pareadas de solo em lavouras sem e com a prática conservacionista vertical mulching. As amostras pareadas foram constituídas por solo representativo de cada lavoura e pelo respectivo sedimento gerado por erosão hídrica. As amostras foram submetidas à determinação de $\mathrm{pH}$ em água, índice SMP, P disponível, K, Ca, Mg e Al trocáveis e matéria orgânica, e calculadas a soma de bases, a saturação por bases e a capacidade de troca de cátions efetiva. Os resultados indicam que a prática conservacionista vertical mulching reduz o grau de enriquecimento do sedimento produzido e previne o carreamento deste para fora da lavoura, minimizando perdas econômicas e riscos à ambiência. Em adição, infere-se que o sistema plantio direto, sem práticas complementares para manejo de enxurrada, não representa manejo conservacionista de solo capaz de prevenir degradação ambiental.
\end{abstract}

Termos de indexação: erosão, chuva, conservação do solo.

\footnotetext{
(1) Trabalho apresentado no XXXI Congresso Brasileiro de Ciência do Solo, 2007 (Gramado, RS).

(2) Pesquisador, Embrapa Trigo, Rodovia BR 285, km 294, Caixa Postal 451, Passo Fundo, RS. E-mails: denardin@cnpt.embrapa.br; rainoldoak@gmail.com; afaganel@cnpt.embrapa.br; arcenio@cnpt.embrapa.br

(3) Estagiário, faculdade de Agronomia, Universidade Federal de Santa Maria, Av. Roraima, 1.000, Cidade Universitária, Bairro Camobi, Santa Maria, RS. Email: diegomanhago@yahoo.com.br
} 


\title{
SUMMARY: VERTICAL MULCHING AS A SOIL CONSERVATION PRACTICE TO MANAGE RUNOFF IN NO TILLAGE SYSTEMS
}

\begin{abstract}
In regions of temperate and subtropical humid climate in Brazil, below the parallel of $24^{\circ}$ latitude South, the rainfall characteristics potentially exceed the soil water infiltration rate and produce runoff, at any time of the year, independent of soil use and management system. The additional conservational practices have not been fully adopted in the no-tillage system as it would be required to control the erosion potential due to the soil conditions of these regions. Runoff results in chemically enriched sediments, which poses environmental risks, besides causing economical losses in the agriculture production system. The objective of this study was to evaluate the efficiency of vertical mulching as a conservation practice to restrict runoff in areas under no-tillage system, by evaluating the sediment enrichment rate based on double soil sampling in fields with presence and absence of the practice of vertical mulching. The double sampling covered representative soils of each plantation and the respective sediments generated by hydric erosion. Soil $\mathrm{pH}$ in water, SMP index, available P, exchangeable $\mathrm{K}, \mathrm{Ca}$, $\mathrm{Mg}$ and $\mathrm{Al}$, and organic matter were determined, and the total and base saturation and cation exchange capacity in each sample were calculated. Results indicate that the conservation practice of vertical mulching reduces the degree of chemical enrichment of the sediments and mainly prevents the transport of these sediments away from plantations, minimizing economical losses and environmental risks. The no tillage system, without complementary conservation practices to control runoff, does therefore not represent a soil conservation practice capable of preventing environmental degradation.
\end{abstract}

Index terms: soil erosion, rainfall, soil conservation.

\section{INTRODUÇÃO}

Nas regiões brasileiras de clima temperado e subtropical úmido, ao sul do paralelo $24^{\circ}$ de latitude sul, em razão das características de distribuição e de intensidade das chuvas, em qualquer época do ano há probabilidade de ocorrência de precipitação pluvial com potencial para formar enxurrada, independentemente do tipo de uso e de manejo de solo (Denardin, 1980). A cobertura de solo por plantas vivas e, ou, por resíduos culturais apresenta potencial para dissipar em até $100 \%$ a energia cinética da chuva, mas não manifesta esta mesma eficiência para dissipar a energia cisalhante da enxurrada. A partir de determinado comprimento de rampa, a energia cisalhante da enxurrada pode superar a tensão crítica de cisalhamento imposta pela cobertura vegetal do solo e permitir a flutuação e o transporte dos restos culturais, bem como a erosão em entre sulcos e, ou, em sulcos sob a cobertura (Bertol, 1995; Bertol et al., 1996; Denardin et al., 2005).

O sistema plantio direto, que na atualidade, representa o manejo conservacionista de solo mais adotado no País, não tem sido implementado com a plenitude conceitual que o expressa como uma ferramenta da agricultura conservacionista para conter o potencial erosivo de chuvas intensas ocorrentes nessas regiões do Brasil (Denardin et al., 2002; Denardin et al., 2004). Contudo, a partir de observações empíricas divulgadas por Martin (1985), foi disseminada a percepção de que o sistema plantio direto constitui prática conservacionista suficiente para controlar integralmente a erosão hídrica. Em decorrência, o terraceamento passou a ser considerado supérfluo e indiscriminadamente desfeito, levado ao abandono da semeadura em contorno e à adoção da semeadura paralela ao maior comprimento da gleba, independentemente do sentido do declive. Como resultante dessas atitudes, tem sido notado, com freqüência alarmante, que a observância parcial das práticas conservacionistas requeridas para as condições edafoclimáticas dessa região do País, fundamentadas apenas na ausência de preparo de solo e na cobertura permanente do solo, otimizadas pelo sistema plantio direto, não tem propiciado condição suficiente para conter o potencial erosivo de chuvas intensas ocorrentes. A associação de práticas conservacionistas ao sistema plantio direto, com eficiência para impor barreira física ao livre escoamento do deflúvio superficial, complementarmente à cobertura permanente de solo, assume relevância, em toposseqüências configuradas por declives acentuados e pendentes longas (Denardin et al., 2003).

A ocorrência de enxurrada em áreas agrícolas, resulta, invariavelmente no transporte de agroquímicos presentes na superfície do solo, que, em decorrência, pode promover prejuízos econômicos e afetar a ambiência. O transporte de corretivos e de fertilizantes, de partículas de solo, de material orgânico e de água para fora da lavoura pode ocasionar poluição de mananciais de superfície, redução do volume de 
água armazenado no solo, redução do tempo de concentração de bacias hidrográficas e redução da recarga de aqüíferos subterrâneos (Schick et al., 2000; Righes et al., 2002a,b; Dalla Costa, 2004). Nesse contexto, qualquer prática conservacionista capaz de manter o comprimento de rampa restrito a limites em que a cobertura de solo não perca eficiência na dissipação da energia cisalhante da enxurrada, contribuirá para minimizar o processo erosivo e os problemas dele decorrentes (Bertol et al., 1996). Assim, ações orientadas à quantificação da magnitude desses problemas são de relevância para subsidiar a qualificação do sistema plantio direto, mediante a implementação de práticas conservacionistas complementares à cobertura de solo, como meio para o efetivo controle da erosão hídrica e para a sustentabilidade da agricultura nessas regiões do Brasil. Dentre as inúmeras práticas conservacionistas destinadas a esse fim, o vertical mulching (Righes et al., 2002a,b; Denardin et al., 2005; Denardin \& Kochhann, 2006a,b) poderá vir a constituir nova opção para aplicação em áreas de pastagem ou manejadas sob sistema plantio direto, por ter apresentado, em ensaios sob chuva simulada e natural, potencial para reduzir em cerca de $76 \%$ o deflúvio superficial (Righes et al., 2002a,b).

O objetivo deste trabalho foi avaliar a eficiência da prática conservacionista vertical mulching no manejo de enxurrada em lavouras sob sistema plantio direto, por meio da quantificação do índice de enriquecimento químico do sedimento produzido.

\section{MATERIAL E MÉTODOS}

O estudo foi desenvolvido nas regiões Planalto Médio e Missões do Estado do Rio Grande do Sul, situadas ao sul do paralelo $24^{\circ}$ de latitude sul e caracterizadas pela probabilidade de ocorrência de chuvas intensas em todos os meses do ano (Denardin et al., 1989), contemplando lavouras produtoras de grãos, estabelecidas sob sistema plantio direto, sem práticas conservacionistas complementares à cobertura de solo para manejo de enxurrada e com a prática conservacionista vertical mulching para manejo de enxurrada (Denardin et al., 2005; Denardin \& Kochhann, 2006a,b), pertencentes aos municípios de Carazinho, Coxilha, Cruz Alta, Ernestina, Júlio de Castilhos, Não-Me-Toque, Passo Fundo, Sarandi, Tapera e Tupancieretã. Os solos das lavouras onde o estudo foi processado são todos pertencentes à classe dos Latossolos Vermelhos distróficos. A amostragem dos sedimentos foi realizada nos meses de maio e junho de 2006, após a colheita da cultura de soja.

A implementação do estudo foi estruturada em dois ensaios, que consistiram de amostragens pareadas de solo, coletadas em diferentes lavouras. O ensaio $1\left(\mathrm{E}_{1}\right)$ contemplou 31 lavouras sob sistema plantio direto sem presença de práticas conservacionistas comple- mentares à cobertura de solo para manejo de enxurrada e o ensaio $2\left(\mathrm{E}_{2}\right)$ contemplou 32 lavouras sob sistema plantio direto com presença da prática conservacionista vertical mulching como prática conservacionista para manejo de enxurrada. As amostras pareadas de solo constituíram os tratamentos $\mathrm{T}_{1}$ e $\mathrm{T}_{2}$. Os tratamentos $\mathrm{T}_{1}$ e $\mathrm{T}_{2}$, do ensaio $\mathrm{E}_{1}$, foram constituídos, respectivamente, por amostras de solo coletadas na área de lavoura e por amostras de solo representativas do sedimento produzido por erosão em sulco na respectiva lavoura. Os tratamentos $\mathrm{T}_{1} \mathrm{e} \mathrm{T}_{2}$, do ensaio $\mathrm{E}_{2}$, foram constituídos por amostras de solo coletadas na área de lavoura situada a montante de cada vertical mulching e por amostras de solo representativas do sedimento depositado no sulco do vertical mulching respectivo.

Nas áreas de lavoura, que constituíram o tratamento $\mathrm{T}_{1}$ de ambos os ensaios, o solo foi amostrado na camada de $0-0,10 \mathrm{~m}$ de profundidade, seguindo a técnica descrita por Sociedade Brasileira de Ciência do Solo (CQFSRS/SC, 2004). A técnica de amostragem de solo para os tratamentos $\mathrm{T}_{2}$ foi específica para cada ensaio: no ensaio $\mathrm{E}_{1}$, a amostragem foi realizada mediante coleta do sedimento depositado a jusante do sulco de erosão e, no ensaio $E_{2}$, a amostragem foi realizada mediante coleta do sedimento depositado no sulco do vertical mulching. As amostras de solo, na camada de $0-0,10 \mathrm{~m}$ de profundidade, foram coletadas com trado tipo calador e as amostras de sedimento foram coletadas com o auxílio de espátula.

As amostras de solo foram processadas no Laboratório de Análise de Solo da Embrapa Trigo sendo determinadas, em cada amostra, as seguintes propriedades: $\mathrm{pH}$ em água, índice SMP, $\mathrm{P}$ disponível, $\mathrm{K}, \mathrm{Ca}, \mathrm{Mg}$ e Al trocáveis, matéria orgânica do solo, soma de bases, saturação por bases e CTC efetiva, seguindo os métodos padronizados pela Sociedade Brasileira de Ciência do Solo (CQFSRS/SC, 2004).

O índice de enriquecimento do sedimento foi obtido pelo quociente do valor de cada propriedade nas amostras representativas do sedimento $\left(\mathrm{T}_{2}\right)$ pelo valor obtido nas amostras coletadas nas lavouras $\left(\mathrm{T}_{1}\right)$. Assim, índices iguais ou inferiores à unidade indicam ausência de enriquecimento do sedimento e índices superiores à unidade indicam enriquecimento do sedimento.

Os resultados de cada propriedade, avaliados em cada ensaio isoladamente, foram tratados estatisticamente pela análise de variância, seguindo o modelo matemático "Observações pareadas", proposto por Steell \& Torrie (1960). Os índices de enriquecimento do sedimento, para cada propriedade avaliada e para cada local de amostragem, observados nos dois ensaios, foram dispostos graficamente para a visualização das tendências de como a presença ou a ausência do vertical mulching altera a qualidade química do sedimento produzido em áreas de lavoura manejadas sob sistema plantio direto. 


\section{RESULTADOS E DISCUSSÃO}

Nos ensaios $\mathrm{E}_{1}$ e $\mathrm{E}_{2}$, sem e com presença da prática conservacionista vertical mulching, respectivamente, contrastando os resultados analíticos das amostras de solo coletadas nas áreas de lavoura $\left(\mathrm{T}_{1}\right)$ com os das amostras de solo coletadas no sedimento $\left(\mathrm{T}_{2}\right)$, verificouse diferença significativa para todas as propriedades avaliadas, indicando enriquecimento químico do sedimento (Quadro 1).

No ensaio $E_{1}$, o coeficiente de variação das propriedades avaliadas oscilou de $3,9 \%$, para o índice SMP, a 56,0 \%, para o Al trocável, e, no ensaio $\mathrm{E}_{2}$, de 4,37 a $62,7 \%$, respectivamente, para as mesmas propriedades. Essa amplitude do coeficiente de variação deveu-se, possivelmente, ao fato de o estudo constituir um levantamento de dados que contemplam lavouras com diferentes tipos de solo, diferentes níveis de fertilidade e submetidas a variados modelos de produção e eventos pluviais. A diferença significativa entre os tratamentos, para todas as propriedades avaliadas, diante de coeficientes de variação dessa magnitude, pode ser atribuída ao fato de ser o enriquecimento do sedimento um processo que se repete em todos os locais levantados.
Dentre as propriedades avaliadas, o P disponível, o K trocável e a matéria orgânica destacaram-se como as de maior enriquecimento de sedimento. No ensaio $\mathrm{E}_{1}$, os valores absolutos de $\mathrm{P}$ disponível, $\mathrm{K}$ trocável e matéria orgânica foram, respectivamente, 3,55, 3,79 e 2,08 vezes maiores nas amostras coletadas no sedimento $\left(\mathrm{T}_{2}\right)$ do que nas amostras coletadas nas lavouras que os geraram $\left(\mathrm{T}_{1}\right)$ e, no ensaio $\mathrm{E}_{2}$, esses valores, em menor magnitude, foram, respectivamente, de 2,96, 2,40 e 1,83. O Al trocável, nas amostras coletadas no sedimento $\left(\mathrm{T}_{2}\right)$, que foi 17 e 7,25 vezes menor do que nas amostras coletadas nas lavouras $\left(\mathrm{T}_{1}\right)$, respectivamente para os ensaios $\mathrm{E}_{1}$ e $\mathrm{E}_{2}$, destacou-se como a propriedade que exibiu a maior diferença entre os dois tratamentos, embora os valores absolutos sejam considerados irrelevantes do ponto de vista da fertilidade do solo. Os maiores teores de $\mathrm{P}$ disponível e de $\mathrm{K}$ trocável observados no sedimento $\left(\mathrm{T}_{2}\right)$, nos dois ensaios, decorreram, possivelmente, da técnica de adubação a lanço na superfície do solo, prática comum em sistema plantio direto. $\mathrm{O}$ menor teor de $\mathrm{Al}$ trocável no sedimento $\left(\mathrm{T}_{2}\right)$ em relação às áreas de lavoura $\left(\mathrm{T}_{1}\right)$, em ambos os ensaios, advieram do transporte preferencial de partículas de calcário de menor diâmetro e, conseqüentemente, de maior reatividade, presentes na superfície do solo, em decorrência da técnica da calagem,

Quadro 1. Propriedades de fertilidade do solo, teste F e coeficiente de variação (CV) determinados em dois ensaios, com dois tratamentos, constituídos por amostras pareadas de solo coletadas em lavouras manejadas sob sistema de plantio direto, sem (ensaio 1) e com (ensaio 2) a prática conservacionista vertical mulching, localizadas em 10 municípios do Planalto Médio e Missões do Estado do Rio Grande do Sul (Embrapa Trigo 2006)

\begin{tabular}{|c|c|c|c|c|c|c|c|c|}
\hline \multirow{2}{*}{ Propriedade $^{(1)}$} & \multicolumn{4}{|c|}{ Ensaio 1 - Erosão em Sulco(2) } & \multicolumn{4}{|c|}{ Ensaio 2 - Vertical Mulching ${ }^{(3)}$} \\
\hline & $\begin{array}{c}\mathrm{T}_{1} \\
\text { Lavoura }\end{array}$ & $\underset{\text { Sedimento }}{\mathbf{T}_{2}}$ & $\begin{array}{c}\text { Teste } \\
\text { F }\end{array}$ & $\begin{array}{l}\text { CV } \\
(\%)\end{array}$ & $\begin{array}{c}\mathrm{T}_{1} \\
\text { Lavoura }\end{array}$ & $\begin{array}{c}\mathbf{T}_{2} \\
\text { Sedimento }\end{array}$ & $\begin{array}{c}\text { Teste } \\
\text { F }\end{array}$ & $\begin{array}{l}\text { CV } \\
(\%)\end{array}$ \\
\hline pH em água & 5,9 & 6,6 & $* *$ & 5,9 & 5,7 & 6,1 & $* *$ & 6,4 \\
\hline Índice SMP & 6,3 & 6,8 & $* *$ & 3,9 & 5,9 & 6,4 & $* *$ & 4,3 \\
\hline Fósforo disponível $\left(\mathrm{mg} \mathrm{dm}^{-3}\right)$ & 14,3 & 50,7 & ** & 44,6 & 23,0 & 68,1 & ** & 51,8 \\
\hline Potássio trocável $\left(\mathrm{mg} \mathrm{dm}^{-3}\right)$ & 104,0 & 394,0 & ** & 35,4 & 201,0 & 482,0 & ** & 42,0 \\
\hline Matéria Orgânica $\left(\mathrm{g} \mathrm{dm}^{-3}\right)$ & 26,0 & 54,0 & ** & 20,6 & 30,0 & 55,0 & $* *$ & 26,2 \\
\hline Alumínio trocável $\left(\mathrm{mmol}_{\mathrm{c}} \mathrm{dm}^{-3}\right)$ & 1,7 & 0,1 & $* *$ & 56,0 & 5,8 & 0,8 & $* *$ & 62,7 \\
\hline Cálcio trocável $\left(\mathrm{mmol}_{\mathrm{c}} \mathrm{dm}^{-3}\right)$ & 44,5 & 60,1 & ** & 17,8 & 46,3 & 53,5 & ** & 13,8 \\
\hline Magnésio trocável $\left(\mathrm{mmol}_{\mathrm{c}} \mathrm{dm}^{-3}\right)$ & 23,2 & 32,3 & ** & 17,0 & 21,1 & 28,5 & ** & 22,1 \\
\hline Soma de bases $\left(\mathrm{mmol}_{\mathrm{c}} \mathrm{dm}^{-3}\right)$ & 70,5 & 102,4 & $* *$ & 16,8 & 72,6 & 94,3 & $* *$ & 17,0 \\
\hline Saturação de bases (\%) & 68,0 & 84,8 & $* *$ & 10,8 & 57,9 & 74,7 & $* *$ & 15,9 \\
\hline CTCe $\left(\mathrm{mmol}_{\mathrm{c}} \mathrm{dm}^{-3}\right)$ & 72,0 & 102,6 & $* *$ & 14,9 & 78,3 & 95,0 & $* *$ & 14,0 \\
\hline
\end{tabular}

(1) $\mathrm{CTCe}=$ capacidade de troca de cátions efetiva. ${ }^{(2)}$ Ensaio 1: Lavouras manejadas sob sistema de plantio direto, sem práticas conservacionistas para controle de enxurrada, em que $\mathrm{T}_{1}$ corresponde a amostras de solo coletadas na área de lavoura do entorno do sulco de erosão e $\mathrm{T}_{2}$ corresponde a amostras de solo representativas do sedimento produzido por este sulco de erosão. Médias de 31 lavouras. ${ }^{(3)}$ Ensaio 2: Lavouras manejadas sob sistema de plantio direto, com a prática conservacionista vertical mulching, em que $\mathrm{T}_{1}$ corresponde a amostras de solo coletadas na área de lavoura situada a montante dos sulcos do vertical mulching e $\mathrm{T}_{2}$ corresponde a amostras de solo representativas do sedimento depositado no sulco do vertical mulching, situado a jusante desta área. Médias de 32 lavouras. 
efetuada sem a incorporação do corretivo ao solo. $\mathrm{O}$ maior teor de matéria orgânica no $\mathrm{T}_{2}$ em relação ao $\mathrm{T}_{1}$, certamente, foi resultante da manutenção dos resíduos culturais na superfície do solo que, pela menor densidade deste material em relação às partículas de solo, passaram a ter transporte preferencial pela enxurrada.

Esses dados permitem inferir que, em áreas manejadas sob sistema plantio direto, a erosão hídrica promove arraste de corretivos, de fertilizantes e de matéria orgânica, presentes na camada mais superficial do solo, gerando sedimento quimicamente enriquecido, que, além de representar prejuízo econômico ao sistema agrícola produtivo, pode constituir fator de poluição ambiental.

Contrastando a magnitude de variação, em valores absolutos, de todas as propriedades analisadas nos ensaios $\mathrm{E}_{1}$ e $\mathrm{E}_{2}$, com destaque para $\mathrm{P}$ disponível, $\mathrm{K}$ trocável e matéria orgânica, percebeu-se que a prática conservacionista vertical mulching reduziu, consideravelmente, o grau de enriquecimento do sedimento produzido (Figura 1), possivelmente por seccionar e, conseqüentemente, diminuir o comprimento da pendente. De outra forma, ao contrário das lavouras manejadas sob sistema plantio direto sem práticas conservacionistas para manejo de enxurrada, ensaio $\mathrm{E}_{1}$, que permitiram o carreamento de sedimento quimicamente enriquecido para fora da lavoura, o vertical mulching reteve o sedimento nos sulcos, prevenindo possível contaminação ambiental, principalmente de mananciais de superfície. Em adição, o ensaio $\mathrm{E}_{2}$, que contemplou o vertical mulching como prática conservacionista para manejo de enxurrada, apresentou potencial para amenizar o problema de enriquecimento de sedimento demonstrado pelas lavouras sem práticas conservacionistas para manejo de enxurrada, ao exibir, para as propriedades $\mathrm{P}$ disponível, $\mathrm{K}$ trocável e matéria orgânica, redução desses índices (Figura 1).

Observando os resultados gerados pelos dois ensaios, pode-se inferir que a prática conservacionista vertical mulching demonstrou potencial para minimizar efeitos danosos da erosão hídrica. Esses dados denotam que a simples adoção do sistema plantio direto, sem práticas conservacionistas complementares à cobertura permanente de solo para manejo de enxurrada, não representa manejo conservacionista de solo capaz de prevenir a degradação ambiental.

\section{CONCLUSÕES}

1. A prática conservacionista vertical mulching reduz o índice de enriquecimento de sedimentos.

2. A prática conservacionista vertical mulching previne o carreamento de sedimento quimicamente enriquecido para fora da lavoura.

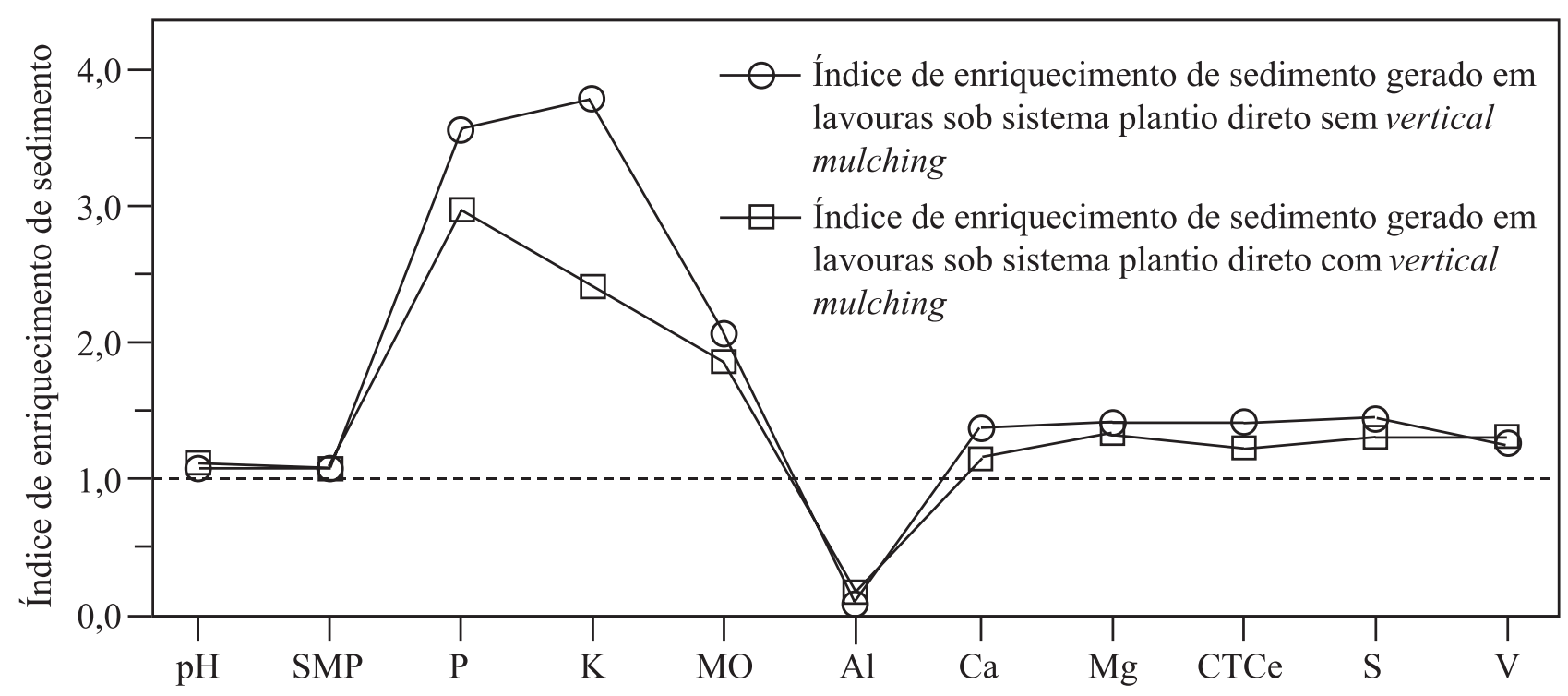

Parâmetros indicadores de fertilidade química do solo

Figura 1. Índices de enriquecimento de sedimento determinados a partir de amostras pareadas de solo coletadas em lavouras manejadas sob sistema de plantio direto, sem e com a prática conservacionista vertical mulching, localizadas em 10 municípios do Planalto Médio e Missões do Estado do Rio Grande do Sul (Embrapa Trigo 2006). 


\section{LITERATURA CITADA}

BERTOL, I. Comprimento crítico de declive em sistemas de preparos conservacionistas de solo. Porto Alegre, Universidade Federal do Rio Grande do Sul, 1995. 185p. (Tese de Doutorado)

BERTOL, I.; COGO, N.P. \& LEVIEN, R. Comprimento crítico de declive em sistemas de preparos conservacionistas de solo. R. Bras. Ci. Solo, 21:139-148, 1996.

COMISSÃO DE QUIMICA E FERTILIDADE DO SOLO . CQFSRS/SC. Manual de adubação e de calagem para os estados do Rio Grande do Sul e Santa Catarina. 10.ed. Porto Alegre, Sociedade Brasileira de Ciência do Solo/ Núcleo Regional Sul, 2004. 400p.

DALLA COSTA, R. Nutrientes na água de escoamento superficial em sistema plantio direto com mulching vertical. Santa Maria, Universidade de Santa Maria, 2004. 63p. (Tese de Mestrado)

DENARDIN, J.E.; BEN, J.R. \& KOCHHANN, R.A. Perdidas de suelo por erosion en el cultivo de soja en Brasil. In: CONFERENCIA MUNDIAL DE INVESTIGACION EN SOJA, 4., Buenos Aires, 1989. Actas-proceedings. Buenos Aires, Asociacion Argentina de la Soja, 1989. p.2204-2210.

DENARDIN, J.E. \& KOCHHANN, R.A. Erosão e práticas mecânicas e vegetativas de conservação de solos em plantio direto. In: FONTOURA, S.M.V. \& BAYER, C., orgs. Manejo e fertilidade de solos em plantio direto. Guarapuava, Fundação Agrária de Pesquisa Agropecuária, 2006a. p.189-217.

DENARDIN, J.E. \& KOCHHANN, R.A. Mulching vertical. In: PIRES, F.R. \& SOUZA, C.M. Práticas mecânicas de conservação do solo e da água. 2.ed. Viçosa, MG, Universidade Federal de Viçosa, 2006b. p.80-85.

DENARDIN, J.E.; KOCHHANN, R.A.; FAGANELLO, A.; SATTLER, A. \& BERTON, A.L. Sistema plantio direto: Com ou sem práticas conservacionistas complementares de manejo da enxurrada? In: CONGRESSO MUNDIAL SOBRE AGRICULTURA CONSERVACIONISTA, 2., Foz do Iguaçu, 2003. Produzindo em harmonia com a natureza: Resumos expandidos e posteres. Foz do Iguaçu, Federação Brasileira de Plantio Direto na Palha; Confederacción de Associaciones Americanas para la Agricultura Sustentavel, 2003. v.2. p.310-313.
DENARDIN, J.E.; KOCHHANN, R.A.; COGO, N.P. \& BERTOL, I. A experiência prático-científica em conservação do solo no Planalto Sul-Rio-Grandense. In: REUNIÃO SULBRASILEIRA DE CIÊNCIA DO SOLO, 4., Porto Alegre, 2002. Solos e qualidade ambiental: resumos expandidos. Porto Alegre, Sociedade Brasileira de Ciência do Solo - Núcleo Regional Sul; UFRGS - Departamento de Solos, 2002. 6p. CD-ROM.

DENARDIN, J.E.; KOCHHANN, R.A.; COGO, N.P. \& BERTOL, I. Terraceamento em sistemas conservacionistas de preparo do solo: II - Análise prática e um relato de caso. In: REUNIÃO BRASILEIRA DE MANEJO E CONSERVAÇÃO DO SOLO E DA ÁGUA, 15., Santa Maria, 2004. Manejo: Integrando a ciência do solo na produção de alimentos. Santa Maria; Universidade Federal de Santa Maria, 2004. 9p. CD-ROM

DENARDIN, J.E.; KOCHHANN, R.A.; FLORES, C.A.; FERREIRA, T.N.; CASSOL, E.A.; MONDARDO, A. \& SCHWARZ, R.A. Manejo de enxurrada em sistema plantio direto. Porto Alegre, Fórum Estadual de Solo e Água, 2005. 88p.

DENARDIN, J.E. Estudo da enxurrada. Curso de manejo e conservação do solo para técnicas de nível superior. Santa Maria, 1980. 12p.

MARTIN, E. O plantio direto no Estado do Rio Grande do Sul. In: ENCONTRO NACIONAL DE PLANTO DIRETO, 3., Ponta Grossa, 1985. Anais. Ponta Grossa, Batavo, Fundação ABC, 1985. p.15-16.

RIGHES, A.A.; DENARDIN, J.E.; KOCHHANN, R.A.; NISHIJIMA, T. \& GARCIA, S.M. "Mulching" vertical e escoamento superficial no sistema plantio direto. In: CONGRESSO BRASILEIRO DE ENGENHARIA AGRÍCOLA, 31., Salvador, 2002. A engenharia agrícola para o desenvolvimento sustentável: água, energia e meio ambiente. Salvador, SBEA/ UFBA/Embrapa, 2002a. 4p.

RIGHES, A. A.; DENARDIN, J. E.; NISHIJIMA, T.; GARCIA, S. M.; HERBES, M. G. Mulching vertical e enxurrada no plantio direto da soja. In: REUNIÃO BRASILEIRA DE MANEJO E CONSERVAÇÃO DO SOLO E DA ÁGUA, 14., 2002, Cuiabá. Resumos... Cuiabá, Universidade Federal do Mato Grosso, 2002b. p.124. CD-ROM.

SCHICK, J.; BERTOL, I. \& BATISTELA, O. Erosão hídrica em Cambissolo Húmico alumínico submitido a diferentes sistemas de preparo e cultivo do solo: Perdas de nutrientes e carbono orgânico. R. Bras. Ci. Solo, 24:437-447, 2000.

STEEL, R.G.D. \& TORRIE, J.H. Principles and procedures of statistics. New York, McGraw-Hill Book Company, 1960. 481p. 